\title{
Cell-Penetrating And Antibacterial BUF-II Nanobioconjugates: Enhanced Potency Via Immobilization On Polyetheramine-Modified Magnetite Nanoparticles
}

This article was published in the following Dove Press journal:

International Journal of Nanomedicine

Jessica Perez (IC)

Javier Cifuentes

Monica Cuellar (1D)

Alejandra Suarez-Arnedo

Juan $C$ Cruz

Carolina Muñoz-Camargo

GINIB Research Group, Department of Biomedical Engineering, Universidad de los Andes, Bogotá, Colombia
Correspondence: Carolina

Muñoz-Camargo; Juan C Cruz

Tel +57-I 3394949 Ext. I789, 1853

Email c.munoz2016@uniandes.edu.co;

jc.cruz@uniandes.edu.co
Introduction: Controlled delivery of therapeutic molecules in a localized manner has become an area of interest due to its potential to reduce drug exposure to healthy tissues and consequently to minimize undesirable side effects. We have recently introduced novel cell-penetrating vehicles by immobilizing the antimicrobial peptide Buforin II (BUF-II) on magnetite nanoparticles (MPNPs). Despite the potent translocating abilities of such nanobioconjugates, they failed to preserve the antimicrobial activity of native BUF-II. In this work, we explored immobilization on MNPs with the aid of polymer surface spacers, which has been considered as an attractive alternative for the highly efficient conjugation of various biomolecules.

Methods: Here, we immobilized BUF-II on polyetheramine-modified magnetite nanoparticles to preserve its structural integrity. As a result, for the obtained nanobioconjugates the lost antimicrobial activity against gram-positive and gram-negative bacteria was only $50 \%$ with respect to the native BUF-II. The nanobioconjugates were also characterized via FTIR, DLS, TEM, and TGA. Delivery on THP-1, HaCaT, HFF, and Escherichia coli cells was conducted to confirm capability for cell membrane translocation.

Results: Colocalization with Lysotracker showed an endosomal escape efficiency of about $73 \mp 12 \%$ in THP-1 cells. Avoidance of endocytic pathways of internalization was qualitatively confirmed by a delivery assay at low temperature. Nuclear penetration of the nanobioconjugates was corroborated via confocal microscopy and showed high biocompatibility as demonstrated by hemolysis levels below 5\% and acute cytotoxicity of around $15 \%$.

Conclusion: The obtained nanobioconjugates were capable of translocating the cell membrane and nuclei of different normal and cancerous cell lines without significantly decreasing viability. This makes the vehicle addressable for a number of applications ranging from antimicrobial topical treatments to the delivery of nucleotides and therapeutic molecules with difficulties to bypass cell membranes.

Keywords: Buforin-II conjugates, drug delivery, translocation, cell-penetrating peptides, nanomaterials

\section{Introduction}

The use of cell-penetrating peptides (CPP's) in systemic drug delivery systems have gained significant attention during the last few years due to possibilities of being used as intracellular delivery vectors of different molecules such as small-drugs, liposomes, peptides, proteins, and oligonucleotides. ${ }^{1}$ Due to their small size, and 
their ability to spontaneously translocate the cell membrane, CPP's have been considered to address one of the major challenges in drug delivery, which is assuring that pharmacological agents are able to come across biological barriers such as the blood-brain barrier. ${ }^{2}$ One of such peptides is Buforin II (BUF-II), which is a 21 -amino acid antimicrobial peptide derived from Bufo bufo gargarizans capable of killing bacteria by interrupting their replication cycle after binding to DNA and RNA. This is achieved by BUF-II after crossing the cell membrane of bacteria without damaging it. ${ }^{3-5}$ This amphipathic peptide is composed by an N-terminal random coil region, an extended helical region, a proline hinge related to the cell-penetrating abilities, and a C-terminal regular a-helical region which has been associated with its antimicrobial activity. ${ }^{6}$ Despite the enormous potential in both drug delivery and as an antimicrobial agent, BUF-II is highly susceptible to proteolytic degradation by endogenous proteases, which reduces its in vitro and in vivo lifespan. ${ }^{6-8} \mathrm{~A}$ strategy to overcome these issues is the conjugation of peptide molecules on drug delivery vehicles such as nanoparticles. This approach has been reported to significantly extend the stability and lifespan of a number of "soft" biomolecules including peptides and enzymes. ${ }^{9,10}$ Moreover, due to their nanosize dimensions, these vehicles are responsible for an increased permeation and retention effect as well as reduced renal clearance. ${ }^{11}$

One of the strategies to confer flexibility to molecules conjugated to the surface of nanostructured materials is by using polypropylene oxide (PPO) or polyethylene oxide (PEO) spacers. A family of polymers that contain both PO and EO moieties in its backbone structure are the polyetheramines (PEAs). They hold terminal primary amine groups either at one end or at the two ends, which could be used to react with carboxyl or hydroxyl groups. ${ }^{12}$ PEAs are commercially available with molecular weights ranging from 200 to $2,000 \mathrm{~g} / \mathrm{mol}$. Due to their unique flexibility and ease for conjugation, the PEAs have been extensively used as modifiers for a number of materials such as carbon fibers, and epoxy resins. ${ }^{13}$

Iron-oxide nanoparticles or magnetite nanoparticles (MNPs) have been widely used in a number of medical applications including drug delivery, ${ }^{14,15}$ MRI imaging, ${ }^{16}$ and hyperthermia for cancer therapy. ${ }^{17}$ The suitability to enable these applications is mainly attributed to the low cytotoxicity of MNPs under most pharmacological regimes and routes of administration. ${ }^{17-20}$ At the same time, MNPs are well suited for guided transport within vascular systems by means of external magnetic fields, and can even be accumulated in specific target organs. ${ }^{21}$ MNPs have been also employed as immobilization supports for biomolecules such as the epidermal growth factor, ${ }^{18}$ albumin, ${ }^{22}$ and bacitracin. ${ }^{23}$ In an attempt to extend the short lifespan of BUF-II and increase the number of active peptides per unit mass, we directly immobilized it on MNPs. ${ }^{24}$ Our findings showed that the cell-penetration ability of BUF-II was preserved after immobilization; however, we observed a complete loss of the antibacterial activity. ${ }^{24}$ Based on these results, we proposed that by incorporating a surface linker prior to immobilization, it was going to be possible to maintain a larger population of peptides with both antibacterial and translocating abilities. Accordingly, here we aimed at evaluating whether immobilization of BUF-II on polymer-modified MNPs helps to maintain its biological activity. Also, we wanted to estimate whether the introduced immobilization route led to detrimental changes in the biocompatibility of the synthesized nanobioconjugates.

\section{Materials And Methods Materials}

Iron (II) chloride tetrahydrate (98\%), dimethylformamide (DMF) (99.8\%), sodium chloride $(\mathrm{NaCl})(99.9 \%)$ and sodium hydroxide $(\mathrm{NaOH})$ (98\%) were obtained from PanReac AppliChem. LysoTracker Green DND-26 was obtained from Life technologies. Iron (III) chloride hexahydrate $(97 \%)$, tetramethylammonium hydroxide (TMAH) (25\%), (3-Aminopropyl) triethoxysilane (APTES) (98\%), LB medium, N-hydroxy succinimide (NHS) (98\%), N-[3dimethylammino)-propyl]-N'-ethyl carbodiimide hydrochloride (EDC) (98\%), dimethyl sulfoxide (DMSO) (99\%), rhodamine B (>95\%), and glutaraldehyde (25\%) were purchased from Sigma-Aldrich. The polyetheramine Jeffamine $^{\circledR}$ M-600 was purchased from Huntsman (600 molecular weight polypropylene glycol monoamine). Dulbecco's modified eagle's medium (DMEM), RPMI 1640 Medium, fetal bovine serum (FBS) and trypsin EDTA were obtained from Biowest. Penicillin/ Streptomycin $(\mathrm{P} / \mathrm{S})$ was purchased from Lonza. Buforin II (BUF-II-TRSSRAGLQFPVGRVHRLLRK) and FITC-BUF2 were synthesized by the Peptide Synthesis Facility at Pompeu Fabra University and GL Biochem Shanghai (Shanghai, China). Purification was performed by HPLC ( $>95 \%)$ and masses were confirmed via mass spectrometry as we did in a previous work. ${ }^{25}$ Delivery 
was conducted in Vero (ATCC ${ }^{\circledR}$ CCL-81), THP-1 (ATCC $^{\circledR}$ TIB-202), HFF (ATCC ${ }^{\circledR}$ SRC-1041), and HaCaT (ATCC ${ }^{\circledR}$ CRL-2404) cells. Bacteria strains were Staphylococcus aureus (ATCC 23235) and Escherichia coli (ATCC 25922).

\section{Labeling Of BUF-II With Rhodamine B}

$1 \mathrm{mg}$ of rhodamine B (1 equivalent) is mixed with $1 \mathrm{mg}$ of EDC (2.5 equivalents) and $1 \mathrm{mg}$ of NHS (4 equivalents) in DMF (with respect to the Carboxyl groups of rhodamine B). The mixture is heated up to $37^{\circ} \mathrm{C}$ under continuous magnetic stirring for 15 mins. This allows activation of the Carboxyl groups to subsequently form amide bonds with the free amine groups of the BUF-II. Finally, $1 \mathrm{~mL}$ of the peptide at $1 \mathrm{mg} / \mathrm{mL}$ is then added to the preactivated rhodamine B and left to react for $24 \mathrm{~h}$ under continuous agitation (200 rpm).

\section{Synthesis And Silanization Of Magnetite Nanoparticles}

Magnetite nanoparticles were synthesized through the chemical coprecipitation method. Briefly, ferric chloride and ferrous chloride were dissolved separately in type II water (water with a resistivity $>1 \mathrm{M} \Omega-\mathrm{cm}$, and conductivity $<1 \mu \mathrm{S} / \mathrm{cm}$ ) to a final concentration of $500 \mathrm{mM}$ and $250 \mathrm{mM}$, respectively. Then, both solutions were simultaneously added dropwise to a $5 \mathrm{M} \mathrm{NaOH}$ solution heated at $90{ }^{\circ} \mathrm{C}$ under continuous agitation. The resulting mixture was left at rest for $1 \mathrm{hr}$ until it reached room temperature. Next, the nanoparticles were washed 10 times with type II water to remove excess reagents. For this purpose, a strong neodymium magnet was used to accelerate the nanoparticle precipitation between each washing cycle. Then, $100 \mathrm{mg}$ of the synthesized nanoparticles were suspended in $30 \mathrm{~mL}$ of type II water. The magnetite nanoparticle suspension was subsequently sonicated for 10 mins. Tetramethylammonium hydroxide solution (TMAH) $(2 \mathrm{~mL}, 25 \%(\mathrm{v} / \mathrm{v}))$ and $50 \mu \mathrm{L}$ of glacial acetic acid were then added to the suspension and sonicated 10 more minutes. (3-Aminopropyl) triethoxysilane (APTES) $(200 \mu \mathrm{L})$ was added to the magnetite solution for silanization. Silanized nanoparticles were washed six times with type II water to remove the excess of APTES aided by a strong neodymium magnet. Finally, silanized particles $(100 \mathrm{mg})$ were resuspended in $30 \mathrm{~mL}$ of type II water. Silanization rendered free amine groups on the surface of the nanoparticles to subsequently conjugate the polyetheramine linker. The synthesis and silanization of magnetite nanoparticles is schematically shown in Figure S1.

\section{Polyetheramine (PEA) M-600 Oxidation And Conjugation On Magnetite Nanoparticles}

We followed the protocol established by Feng et al. ${ }^{26}$ to oxidize the methoxyethyl termination of the PEA Jeffamine $^{\circledR}$ M-600. Briefly, PEA Jeffamine ${ }^{\circledR}$ M-600 and an excess amount of $\mathrm{KMnO}_{4}$ (1:2 molar ratio) were dissolved in $150 \mathrm{~mL}$ of type II water. The solution was left to react under constant magnetic stirring for $12 \mathrm{~h}$ at room temperature. Upon oxidation, the resulting $\mathrm{MnO}_{2}$ byproduct was filtered out under vacuum to obtain a colorless homogeneous solution. Excess $\mathrm{KMnO}_{4}$ and hydrazine byproduct were removed by dialysis against type II water for $24 \mathrm{~h}$ using a membrane cassette with a 1000 cut-off molecular weight. A rotary evaporator was then used to concentrate the oxidized PEA for $6 \mathrm{~h}$ at $70^{\circ} \mathrm{C}$. PEA-coated magnetite nanoparticles were obtained by mixing $100 \mathrm{mg}$ of silanized nanoparticles in $30 \mathrm{~mL}$ of type II water along with $1 \mathrm{~mL}$ of $2 \%(\mathrm{v} / \mathrm{v})$ glutaraldehyde-type II water solution. After 30 mins of reaction at room temperature, the oxidized PEA solution was added in a molar ratio 1:2 and stirred overnight. Finally, PEA-coated magnetite nanoparticles were washed 6 times with type II water. Finally, the nanoparticles were resuspended in $30 \mathrm{~mL}$ of type II water for the subsequent immobilization of Buforin II. The conjugation of PEA on magnetite nanoparticles is schematically shown in Figure S1.

\section{Conjugation Of BUF-II On PEA-Modified Magnetite Nanoparticles}

To obtain the BUF-II-PEA-magnetite nanobioconjugates (Figure 1A), $100 \mathrm{mg}$ of PEA-coated magnetite were suspended in $30 \mathrm{~mL}$ of distilled water and sonicated for 10 mins. BUF-II was conjugated to the Carboxyl groups of oxidized PEA (1 equivalent) by its $\mathrm{N}$-terminal to form amide bonds with the aid of two equivalents of EDC and 2 equivalents of NHS (with respect to the Carboxyl groups). Briefly, $500 \mu \mathrm{L}$ of unlabeled or labeled BUF-II solution at $1 \mathrm{mg} / \mathrm{mL}$ in sterile $\mathrm{NaPB}$ were mixed with the EDC/NHS pre-dissolved in DMF and were subsequently added to the nanoparticle suspension. The mixture is sonicated for 5 more minutes and left to react for $24 \mathrm{~h}$. After conjugation, samples were 
A)

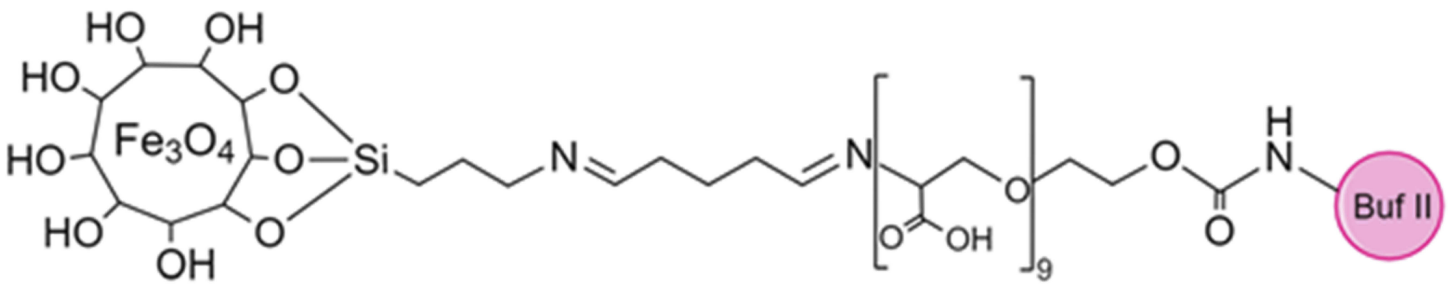

B)

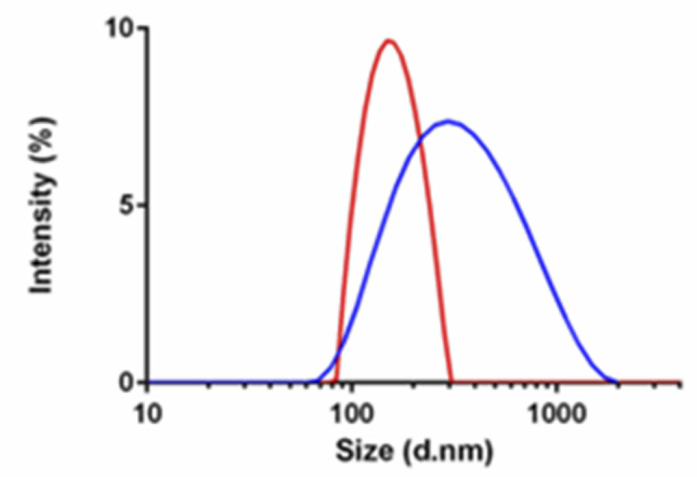

D)

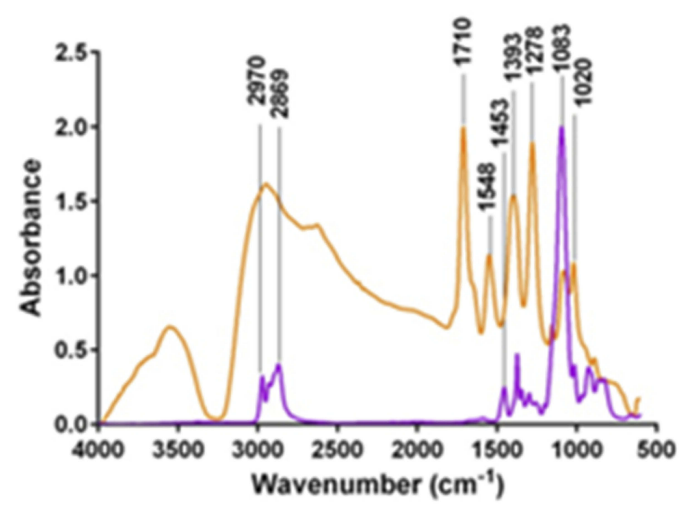

C)

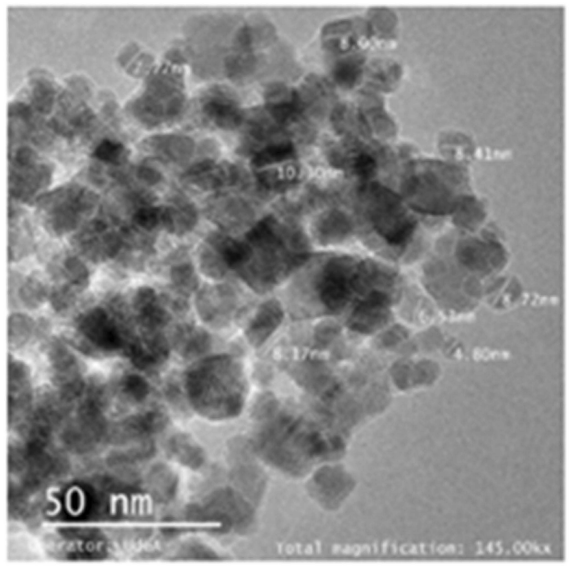

E)

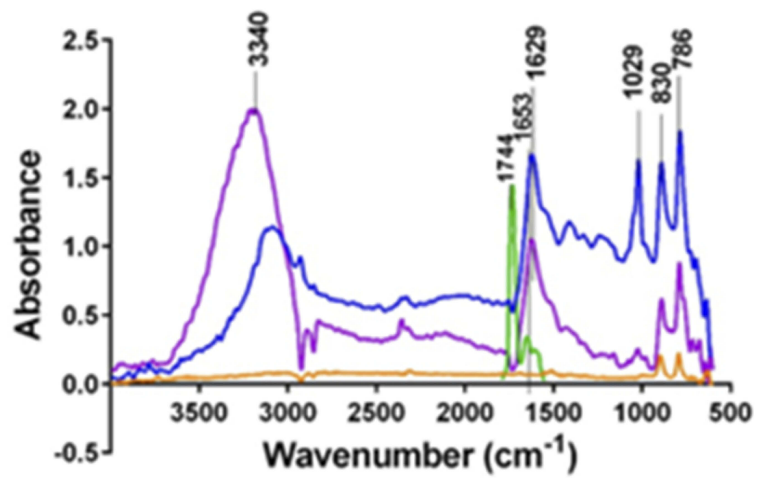

F)

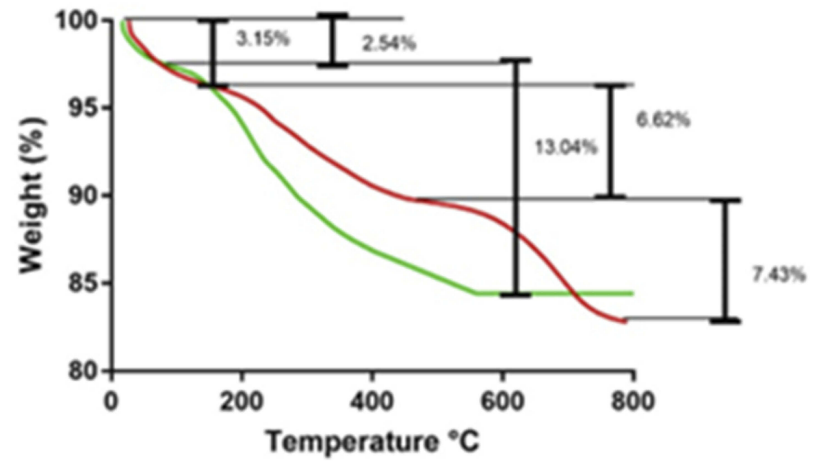

Figure I (A) Schematic of the chemical structure of the nanobioconjugate. (B) DLS histogram for the size distribution of magnetite nanoparticles (red) and BUFII-PEA-Magnetite nanobioconjugates (blue). (C) TEM micrograph of the BUFII-PEA-Magnetite nanobioconjugates with the approximate diameters of individual particles (D) FTIR spectra of oxidized PEA (orange), and PEA (purple). (E) FTIR spectra of bare magnetite (orange), PEA-coated magnetite (blue), BUF-II (green) and BUFII-PEA-Magnetite nanobioconjugates (purple). (F) TGA thermograms of magnetite (green) and BUFII-PEA-Magnetite nanobioconjugates (red). The first weight loss steps (2.54 and 3.15\%) represent the dehydration of the samples. Second weight loss steps $(6.62 \%$ and $13.04 \%)$ correspond to physically adsorbed organic solvents. The final weight loss step (7.43\%) is attributed to the detachment of BUF-II from the nanoparticle's surface. 
thoroughly washed with Type 1 water (Ultrapure water with a resistivity $>18 \mathrm{M} \Omega-\mathrm{cm}$, and conductivity $<0.056$ $\mu \mathrm{S} / \mathrm{cm}$ ) and the aid of a strong permanent magnet to remove excess reagents. The conjugation of BUF-II on PEA-modified magnetite nanoparticles is schematically shown in Figure S1.

\section{Characterization Of BUF-II-PEA- Magnetite Nanobioconjugates}

The hydrodynamic diameter was determined through DLS (Zeta-Sizer Nano-ZS, Malvern, UK) using a solution of magnetite in ethanol $(3 \% \mathrm{w} / \mathrm{v})$ at $37^{\circ} \mathrm{C}$ to simulate body temperature. A 200kV FEI Tecnai F20 Super-Twin TEM was used to determine the size of the nanobioconjugate in the solid state. Sequential surface modifications of magnetite nanoparticles with APTES, Oxidized PEA, and BUF-II were evaluated via Fourier Transform Infrared Spectroscopy (FTIR) by a Bruker Alpha II FTIR Eco-ATR (Bruker, Germany). Spectra were collected in the range of $4,000-400 \mathrm{~cm}^{-1}$ with a spectral resolution of $2 \mathrm{~cm}^{-1}$. Thermogravimetric analysis (TGA) was carried out by ramping up the temperature of a $10 \mathrm{mg}$ sample at a rate of $10^{\circ} \mathrm{C} / \mathrm{min}$ from 25 to $800^{\circ} \mathrm{C}$ in a simultaneous TGA/DSC instrument (TA Instruments, USA).

\section{Antibacterial Activity Assay}

Antibacterial activity was assayed by the broth microdilution assay as described by Park et al. ${ }^{6}$ Briefly, bacterial cells from $S$. aureus and E.coli were cultured overnight in $\mathrm{LB}$ medium at $37^{\circ} \mathrm{C}$; an aliquot of this culture was taken and incubated in fresh medium until a McFarland standard of 0.5 was achieved. Four concentrations $(1,000,750,500$ and $100 \mu \mathrm{g} / \mathrm{mL})$ of BUF-IIPEA-magnetite conjugates were assayed, as well as two concentrations of BUF-II $(100 \mu \mathrm{M}$ and $3.125 \mu \mathrm{M})$. Then, $50 \mu \mathrm{L}$ of each treatment were seeded by triplicate on a 96-well microtiter plate (TPP). After bacterial cells reached mid-logarithmic phase, cells were centrifuged, washed three times with $10 \mathrm{mM}$ sodium phosphate buffer (NaPB, pH 7.4) and diluted $1: 10,000$ in the same buffer. Then, $50 \mu \mathrm{L}$ of the diluted cells were added to $50 \mu \mathrm{L}$ of each of the treatments and incubated for $3 \mathrm{hrs}$ at $37^{\circ} \mathrm{C}$. After incubation, $100 \mu \mathrm{L}$ of fresh $\mathrm{LB}$ medium was added to each well and incubated for $18 \mathrm{hrs}$ at $37^{\circ} \mathrm{C}$. Inhibitory growth effects were evaluated by absorbance at $620 \mathrm{~nm}^{22}$

\section{Bacteria Translocation And Morphological Changes}

Bacteria translocation and morphological changes were evaluated in E. coli via Atomic Force Microscopy (AFM, MFP-3D-BIO, Asylum Research, UK) and Scanning Electron Microscope (SEM, TESCAN Lyra 3, Czech Republic). E. coli cells were cultivated at $37^{\circ} \mathrm{C}$ in $\mathrm{LB}$ medium until Log Phase was achieved at a concentration equivalent to an optical density of $\sim 0.2$ at $620 \mathrm{~nm}$. Then, $E$. coli in the presence nanobioconjugates were washed twice with PBS 1X (137 mM NaCl, $10 \mathrm{mM}$ phosphate, $2.7 \mathrm{mM} \mathrm{KCl}$; pH 7.4) and fixed onto glass slides for $2 \mathrm{hrs}$ at room temperature with $2.5 \%(\mathrm{v} / \mathrm{v})$ glutaraldehyde. After fixation, bacteria were washed twice with PBS $1 \mathrm{X}$ and stored at $4{ }^{\circ} \mathrm{C}$ prior to the AFM measurement. ${ }^{27}$ AFM images were acquired by using the Magnetic Force Microscopy module of the instrument. Measurements were started by randomly scanning areas of $7 \times 7 \mu \mathrm{m}^{2}$ with the purpose of finding sufficient bacterial cells for imaging. Images were collected for bacteria in the presence and absence of the nanobioconjugates. Both morphological changes and magnetic response were evaluated in the samples. Amplitude, height, and voltage images were recorded simultaneously. Topography from height images was used to calculate the roughness of the bacterial cell surface based on the root mean square (RMS) values, which in turn, are based on the standard deviation of all the height values within a given area. ${ }^{28}$ Amplitude images were captured to analyze size profiles of bacteria, while voltage images helped to determine the presence of the nanobioconjugates inside bacteria. For SEM imaging, samples (bacteria, nanobioconjugate in the presence of bacteria, and only the nanobioconjugate) were cultured as described above and subsequently washed six times with Milli Q water, prior to fixing them on a conducting tape in an aluminum base via evaporation. SEM images were acquired at an accelerating voltage (HV) of $10 \mathrm{kV}$ to guarantee a higher penetration into the sample and provide more information on the layer beneath the surface. The collected signal was acquired via secondary electrons (SE) and backscattered electrons (BSE) signal. Finally, image analysis was performed on Image ${ }^{\circledR}$.

\section{Cell Translocation And Endosome Escape} Cell translocation of the nanobioconjugate BUF-II-PEAcoated magnetite was evaluated in monocytes from acute monocytic leukemia (THP-1), keratinocytes from an 
aneuploid immortal cell line (HaCaT) and human foreskin fibroblasts (HFF). Briefly, fluorescently labeled peptide (BUFII-FTIC and BUFII-Rhodamine B) was conjugated to PEA-coated magnetite as described above and subsequently co-delivered with DAPI to cells at a dilution ratio of 1:100 in $1 \mathrm{~mL}$ of the corresponding medium (DMEM for HaCaT and HFF and RPMI for THP1, 10\% FBS and $1 \% \mathrm{P} / \mathrm{S}$ ). Samples were incubated for $1 \mathrm{hr}$ at $37^{\circ} \mathrm{C}$ and $5 \%$ $\mathrm{CO}_{2}$ prior to confocal observation on the Olympus FV1000 microscope.

Additionally, the ability of nanobioconjugates to escape endosomal routes of internalization was assessed in THP-1 cells. For this purpose, BUFII-Rhodamine B-PEA-Magnetite conjugates were co-delivered with the endosomal marker LysoTracker green DND-26 and incubated for $1 \mathrm{hr}$ at $37^{\circ} \mathrm{C}$ and $5 \% \mathrm{CO}_{2}$. To confirm if the cellular internalization in THP-1 cells was energy-independent, cells $(100,000$ cells $/ 35 \mathrm{~mm}$ petri dish) were incubated with BUFII-Rhodamine B-PEA-Magnetite nanobioconjugates for $1 \mathrm{~h}$ at $37^{\circ} \mathrm{C}$ and $5 \% \mathrm{CO}_{2}$ prior to observation at either $37^{\circ} \mathrm{C}$ or $4^{\circ} \mathrm{C}$. Also, a sample of the cells incubated at $37^{\circ} \mathrm{C}$ was incubated for 2 more hours at $4^{\circ} \mathrm{C}$ prior to observation. Imaging was conducted on an Olympus FV1000 confocal laser scanning microscope (CLSM) with a PlanApo 60x, 1.35 NA oil-immersion objective. Samples labeled with Rhodamine B and DAPI were imaged by exciting with the $550 \mathrm{~nm}$ and $347 \mathrm{~nm}$ lasers, respectively. Imaging was conducted at different positions throughout the culture depth to ensure a complete z-stack scan. Image analysis was performed in ImageJ and Fiji (https://imagej.net/Fiji/Downloads).

\section{Nanobioconjugate Uptake In Mammalian Cells}

Nanobioconjugate uptake by mammalian cells THP-1 was evaluated by a decrease in the fluorescence intensity upon internalization of the labeled nanobioconjugates (BUFIIRhodamine B-PEA-Magnetite) in cells, using a Synergy HT Multi-Mode Reader (BioteK) Spectrofluorometer. Briefly, THP-1 cells were cultured in DMEM media supplemented with $10 \% \mathrm{FBS}$ and $1 \% \mathrm{P} / \mathrm{S}$, at $37^{\circ} \mathrm{C}$ and $5 \%$ $\mathrm{CO}_{2}$, until an $80 \%$ confluency was reached. Cells were seeded at $3 \times 10^{4}$ cells/well on a 96-well microtiter plate and exposed to the nanobioconjugates in concentrations ranging from $6.25 \mu \mathrm{g} / \mathrm{mL}$ to $500 \mu \mathrm{g} / \mathrm{mL}$. Cells were then incubated for $1 \mathrm{hr}$ at $37^{\circ} \mathrm{C}$ and $5 \% \mathrm{CO}_{2}$. Fluorescence intensity was collected at $530 \mathrm{~nm}$ of excitation and
$635 \mathrm{~nm}$ of emission. Data was converted into internalization percentage with the aid of a previously prepared calibration curve of Intensity vs Nanobioconjugate concentration.

\section{Biocompatibility}

Biocompatibility of the nanobioconjugates was evaluated by assessing its cytotoxic, hemolytic and platelet aggregation capacities. Cytotoxicity was evaluated on Vero cells cultured at $37^{\circ} \mathrm{C}$ and $5 \% \mathrm{CO}_{2}$ in DMEM media supplemented with $10 \% \mathrm{FBS}$ and $1 \% \mathrm{P} / \mathrm{S}$. Cells were plated at 3 $\times 10^{4}$ cells/well in a 96-well microtiter plate and exposed to two-fold dilutions of nanobioconjugate by triplicate starting at $100 \mu \mathrm{g} / \mathrm{mL}$ down to $6.25 \mu \mathrm{g} / \mathrm{mL}$ during $24 \mathrm{~h}$ and $72 \mathrm{~h}$ of incubation at $37^{\circ} \mathrm{C}$ and $\mathrm{CO}_{2}$, cell toxicity was then evaluated by lactate dehydrogenase (LDH) assay. Briefly, after incubation, $100 \mu \mathrm{L}$ of supernatant was transferred to a new 96-well plate along with 100 of LDH reaction mixture and left to react for 30 mins. Absorbance from LDH release was quantified at $490 \mathrm{~nm}$ wavelength and $650 \mathrm{~nm}$ as the reference value. As a negative control, cells without treatment were used and as the positive control, cells were treated with DMSO. The hemolytic activities of the nanobioconjugate were assessed as described by Muñoz et al. ${ }^{25}$ Briefly, $2 \times 10^{7}$ erythrocytes from a human blood healthy donor were centrifuged and washed three times with $\mathrm{NaCl} 150 \mathrm{mM}$ and then replaced with $1 \mathrm{~mL}$ of PBS $1 \mathrm{X}$. $50 \mu \mathrm{L}$ of erythrocytes were mixed by triplicate along $50 \mu \mathrm{L}$ of the conjugate at serially diluted concentrations in PBS $1 \mathrm{X}$ starting at $100 \mu \mathrm{g} / \mathrm{mL}$ down to $6.25 \mu \mathrm{g} / \mathrm{mL}$, in a 96-well microtiter plate and incubated at $37^{\circ} \mathrm{C}$ for one hour. Mili Q water was used as the positive control and PBS $1 \mathrm{X}$ as the negative control. After incubation, the microtiter plate was centrifuged and the absorbance of each supernatant was measured at $450 \mathrm{~nm}$.

The effect of BUF-II-PEA-coated magnetite nanobioconjugates, bare magnetite and PEA-coated magnetite nanoparticles on platelet aggregation was evaluated using platelet-rich plasma (PRPs). Positive controls of aggregation were epinephrine, adenosine diphosphate (ADP) and collagen. PRPs were obtained by centrifugation of a sample of human blood in sodium citrate at $1000 \mathrm{rpm}$. Twofold serially diluted concentrations of the treatment (nanobioconjugates, bare magnetite, and PEA-coated-magnetite) were evaluated starting at $100 \mu \mathrm{g} / \mathrm{mL}$ down to $12.5 \mu \mathrm{g} / \mathrm{mL}$ after 3 mins of exposure to the treatments. Negative controls were PRPs in the absence of materials and PRPs in 
PBS 1X. Aggregation was measured by absorbance at $620 \mathrm{~nm}$.

\section{Results And Discussion Nanoparticles Characterization}

Figure 1A shows a schematic of the obtained nanobioconjugates after all functionalization steps and final conjugation of BUFII-Rhodamine B. Figure 1B shows the hydrodynamic diameter distribution of bare magnetite nanoparticles and nanobioconjugates as determined by DLS. Bare magnetite nanoparticles exhibited a mean hydrodynamic diameter of $130 \mathrm{~nm}$ with a polydispersity index (PI) of $14.66 \%$. After conjugation of BUF-II, the hydrodynamic diameter increased to $295 \mathrm{~nm}$ with a PI of $25.6 \%$. The sizes and PIs obtained prior to the conjugation of BUF-II are comparable to those obtained in our previous work $^{24}$ but are larger to monodisperse MNP suspensions obtained by others under a nitrogen-controlled atmosphere ${ }^{29}$ or by precisely adjusting stirring speed during the co-precipitation process. ${ }^{30}$ Upon conjugation of BUF-II; however, the obtained size and PI is larger compared with our previous work. This can be attributed to the presence of the PEA polymer linker on the surface that is likely to promote aggregation. TEM images show aggregates with individual particles exhibiting an average diameter of $7.84 \mathrm{~nm} \pm 1.61 \mathrm{~nm}$ (Figure 1C), which agrees well with the sizes found by Ling (about $4 \mathrm{~nm})^{30}$ and Karimzadeh $(14.7 \mathrm{~nm}){ }^{30}$ The size of the obtained nanobioconjugates appears attractive for applications where a sustained accumulation of the delivery vehicles is required for a long-lasting therapeutic effect. This is the case of cancerous tumors where accumulation has been reported for nanoparticles with diameters above $20 \mathrm{~nm}$. In contrast, nanoparticles with diameters below $5.5 \mathrm{~nm}$ tend to be easily cleared by the renal excretory system. ${ }^{31,32}$ Sizes of aggregates from DLS and TEM measurements are not comparable because of the differences in the state of the samples during their evaluation. In the first case, the sample is suspended in an aqueous medium while in the second the material is dried out for observation, which leads to uncontrolled aggregation processes. ${ }^{33,34}$

Surface modifications of magnetite nanoparticles and PEA oxidation were confirmed by Fourier transformed infrared spectroscopy (FTIR) and thermogravimetric analysis (TGA). Figure 1D shows the FTIR spectra of PEA and oxidized PEA. Prior to oxidation, FTIR spectrum of PEA shows two absorption bands at around $1,083 \mathrm{~cm}^{-1}$, which can be attributed to a C-O-H stretching and an additional band at $1,453 \mathrm{~cm}^{-1}$, which can be correlated with the $\mathrm{C}-\mathrm{H}$ bending. ${ }^{35}$ Compared to the PEA IR spectrum, oxidized PEA exhibits four different vibrational bands at about 1,710, 1,548, 1,393 and $1,278 \mathrm{~cm}^{-1}$, which can be explained by the presence of $\mathrm{C}=\mathrm{O}$ stretching, $\mathrm{N}-\mathrm{O}$ stretching, $\mathrm{C}-\mathrm{H}$ bending and $\mathrm{O}-\mathrm{H}$ stretching, respectively. Of particular interest is the $\mathrm{C}=\mathrm{O}$ stretching because it can be associated with the carboxyl groups needed for the conjugation of BUFII. As shown in Figure 1E, bare magnetite exhibited absorption bands at around $632 \mathrm{~cm}^{-1}$ and $585 \mathrm{~cm}^{-1}$, which can be attributed to the $\mathrm{Fe}-\mathrm{O}$ bond of iron oxide. $^{18,29}$ The presence of the Si-O stretching vibration at about $1,029 \mathrm{~cm}^{-1}$ and bending vibrations of $\mathrm{C}-\mathrm{H}$ at $1391 \mathrm{~cm}^{-1}$ and N-H bands at $1,653 \mathrm{~cm}^{-1}$, confirmed the silanization with APTES. ${ }^{30,36}$ Conjugation of PEA on silanized magnetite was confirmed by an absorption peak at about $1,629 \mathrm{~cm}^{-1}$, which is due to the presence of the $\mathrm{C}=\mathrm{O}$ stretching in the backbone of the polymer. Finally, conjugation of BUF-II was verified by the presence of the amide band at $1,650 \mathrm{~cm}^{-1}$, which can be related to the $\alpha$-helix region in the secondary structure of BUF-II. Further confirmation was provided by a band at $1,565 \mathrm{~cm}^{-1}$, which can be attributed to the N-H and $\mathrm{C}-\mathrm{N}$ bonds of the peptide, as well as a band at about $1,744 \mathrm{~cm}^{-1}$, which can be explained by dehydrated carbonyl groups. ${ }^{37}$

Conjugation efficiency of BUF-II on the surface of magnetite nanoparticles was estimated via TGA (Figure 1F). Magnetite and BUF-II-PEA-magnetite (MPB) conjugates exhibited a first weight loss of $2.54 \%$ and $3.15 \%$ mainly due to dehydration of the samples. Bare magnetite had a second weight loss of $13.04 \%$ while for the MPB was of $6.62 \%$. These losses are attributed to physically adsorbed organic compound residues left by the synthesis and functionalization processes. Finally, the detachment of BUF-II from the magnetite was estimated with a final weight loss step of $7.43 \%$. These weight losses agree well with those found in our previous work. ${ }^{24}$

\section{Antibacterial Activity}

Antibacterial activity was determined by broth microdilution assay using Gram-positive (S. aureus) and Gramnegative bacteria (E. coli). Additionally, based on the evidence that antimicrobial activity of AMPs in presence of high concentrations of salt are reduced, we 
evaluated the impact of salt (Low salt LB and LB broth medium) on the antibacterial activity of the nanobioconjugates. $^{38,39}$ Our results demonstrated that the antibacterial activity of BUF-II-PEA-magnetite conjugates is preserved for all evaluated salt concentrations (Figure 2A). At $1 \mathrm{mg} / \mathrm{mL}$, BUF-II-PEA-magnetite conjugates reduced bacterial growth in $S$. aureus and $E$. coli by about $50 \%$ while at $750 \mu \mathrm{g} / \mathrm{mL}$ growth was reduced by about $35 \%$ for $E$. coli and $50 \%$ for $S$. aureus. Finally, at $500 \mu \mathrm{g} / \mathrm{mL}$ and $100 \mu \mathrm{g} / \mathrm{mL}$, bacterial growth was also reduced by $45 \%$ and $20 \%$ for $S$. aureus while for $E$. coli the reduction was about $22 \%$, and $18 \%$; respectively. These results demonstrated that as opposed to our previous study, ${ }^{24}$ immobilization on PEA-modified magnetite nanoparticles is a suitable route to maintain a larger number of BUF-II molecules with activity against both gram-positive and gram-negative bacteria. Bare nanoparticles show no antibacterial activity in the presence of either E. coli or S. aureus (data not shown).

\section{Membrane Integrity And Internalization In Bacteria}

Figure 3 shows AFM images of $E$. coli in the absence and presence of BUF-II-PEA-magnetite nanobioconjugates (Figure 3A and B). Height profiles (Figure 3C) and surface roughness for a representative bacterium cell in the absence (Figure 3D) and presence (Figure 3E) of nanobioconjugates were plotted with the aid of the open-source software Gwyddion ${ }^{\circledR}$. The height profiles showed no significant changes in size for the bacterium after exposure to the conjugates. Surface roughness also remained unaltered in the presence of the conjugates. Taken together, these two findings strongly suggest that penetration of the conjugates into $E$. coli proceeds without promoting significant

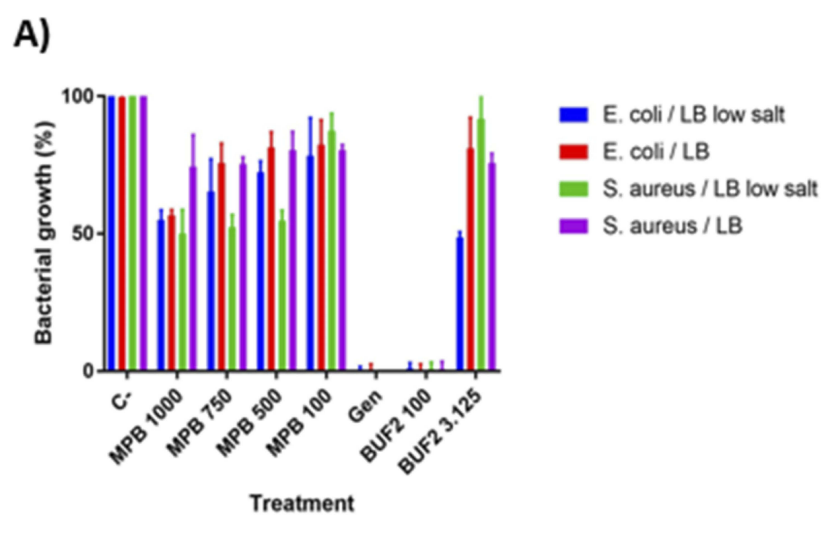

C)

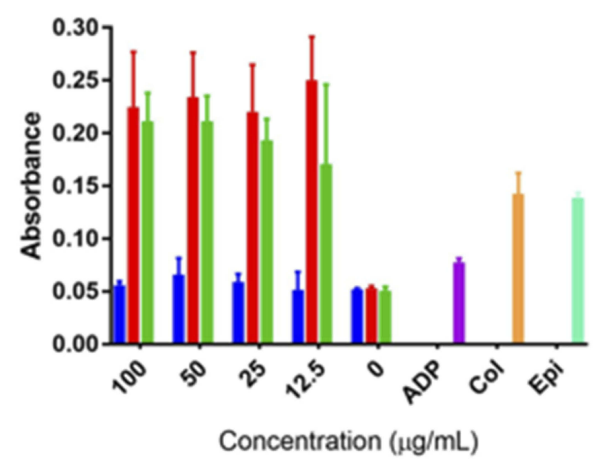

B)

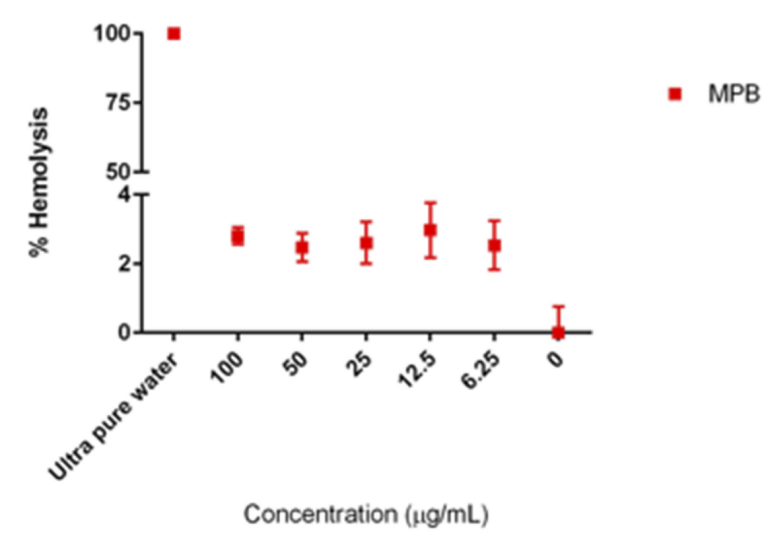

D)

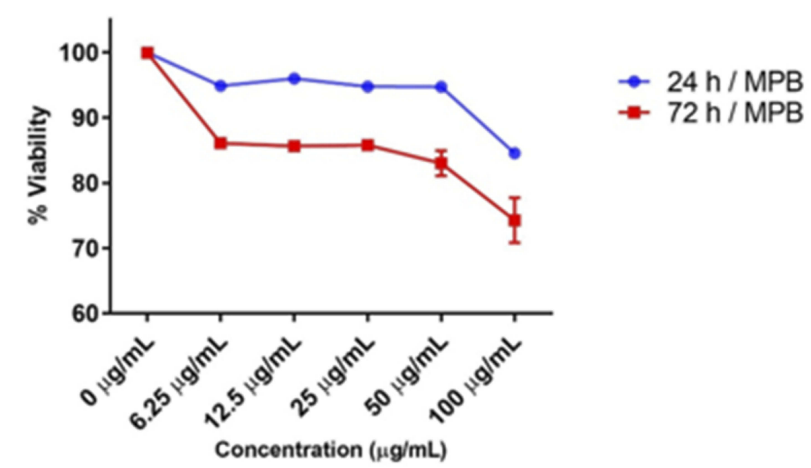

Figure 2 (A) Bacterial growth after treatments with BUF-II-PEA-magnetite nanobioconjugates at I mg/mL, $750 \mu g / \mathrm{mL}, 500 \mu \mathrm{g} / \mathrm{mL}$ and I00 $\mu \mathrm{g} / \mathrm{mL}$ (MPB I000, MPB 750, MPB 500 and MPB 100), gentamicin (Gen) and BUF-II at $100 \mu \mathrm{M}$ and $3.125 \mu \mathrm{M}$ (BUF-II 100 and BUF-II 3.I25). (B) Assessment of the hemolytic effect of BUF-II-PEA-magnetite nanobioconjugates (MPB) at different concentrations. In all cases, hemolysis was below 5\%. Mili $Q$ water was used as a positive control and PBS IX as the negative control. (C) Platelet aggregation caused by bare magnetite (blue), PEA-coated magnetite nanoparticles (red) and BUF-II-PEA-magnetite nanobioconjugates (green) compared to Adenosine diphosphate (ADP), collagen (Col), Epinephrine (Ep), and Buforin II (BUF-II) (D) Cytotoxicity of BUF-II-PEA-magnetite nanobioconjugates at 24 (blue) and 72 hrs (red). Abbreviations: MS, bare magnetite; MP, PEA-coated magnetite; MPB, BUF-II-PEA-magnetite conjugates. 


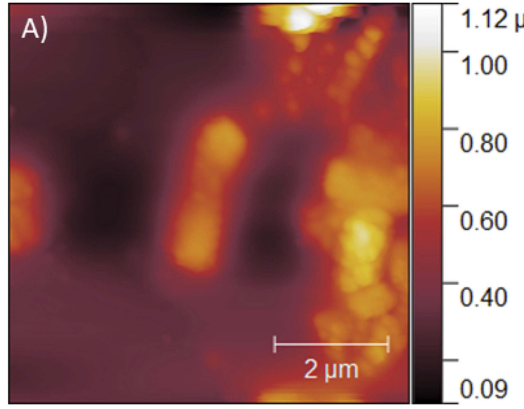

D)

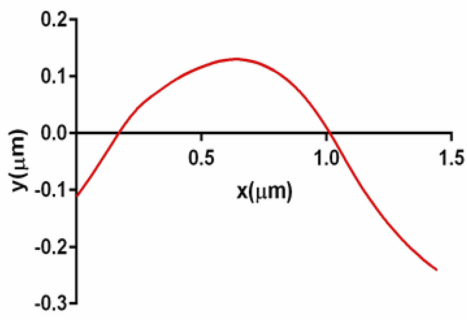

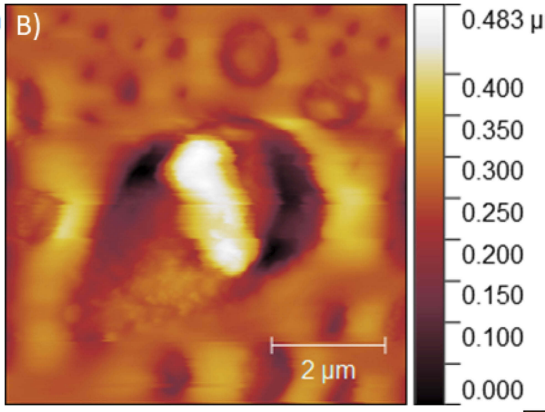

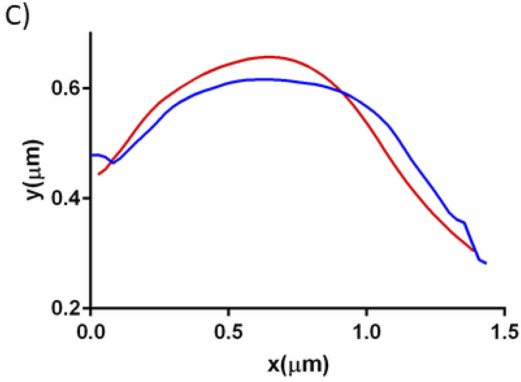

E)

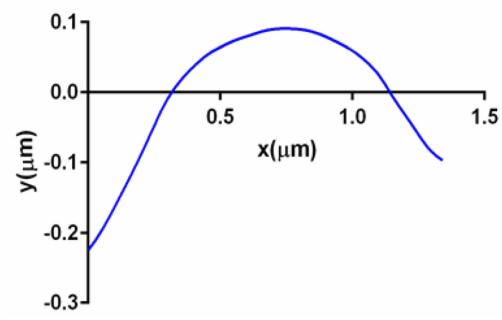

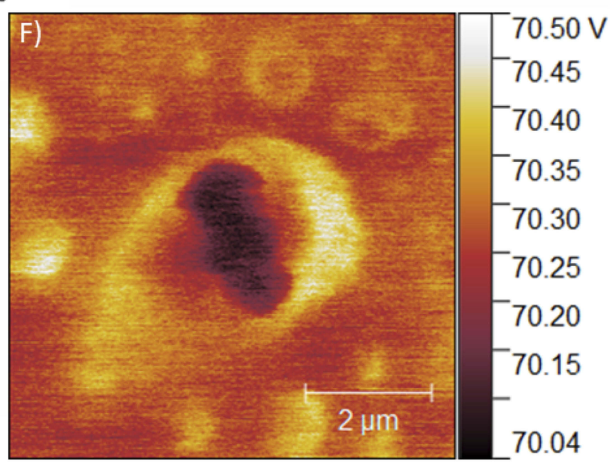

Figure 3 AFM height images of (A) E. coli (B) E. coli in the presence of BUF-II-PEA-magnetite nanobioconjugates (C) Height profiles of $E$. coli (red) and E. coli in the presence of BUF-II-PEA-magnetite nanobioconjugates (blue) (D) E. coli roughness profile for $E$. coli (red) and (E) $E$. coli in the presence of BUF-II-PEA-magnetite nanobioconjugates (blue) (F) Electrostatic force on a single bacterium after exposure to the BUF-II-PEA-magnetite nanobioconjugate.

membrane perturbation. A mask was imposed on cells aided by Gwyddion ${ }^{\circledR}$ to evaluate mean square roughness or RMS of height irregularities $\left(\mathrm{S}_{\mathrm{q}}\right)$ and mean roughness or $\mathrm{S}_{\mathrm{a}}$ value of height irregularities. Even though $\mathrm{S}_{\mathrm{q}}$ and $\mathrm{S}_{\mathrm{a}}$ are computed from the 2 nd central moment of data values, the first is calculated from the sum of absolute values of data differences from the mean, while the second is from the differences from their squares. Table 1 summarizes the calculated values for each parameter in the presence and absence of the nanobioconjugates. The higher values of $\mathrm{S}_{\mathrm{q}}$ and $S_{a}$ for the analyzed bacterium in the absence of the conjugates suggests that upon entrance into the microorganisms, conjugates are most likely responsible for promoting surface perturbations that ultimately lead to the release of weakly interacting molecules such as buffer salts. According to a recent AFM study on E. coli, $\mathrm{S}_{\mathrm{q}}$

Table I Cell Morphology Of E. Coli

\begin{tabular}{|l|l|l|}
\hline Parameter & E. coli & $\begin{array}{l}\text { E. coli + BUF-II-PEA- } \\
\text { Magnetite }\end{array}$ \\
\hline $\begin{array}{l}\text { Roughness Mean } \\
\text { Square }\left(\mathrm{S}_{\mathrm{q}}\right)\end{array}$ & $\begin{array}{l}56.90 \mathrm{~nm} \pm \\
0.69 \mathrm{~nm}\end{array}$ & $21.67 \mathrm{~nm} \pm 1.14 \mathrm{~nm}$ \\
Mean Roughness $\left(\mathrm{S}_{\mathrm{a}}\right)$ & $\begin{array}{l}47.07 \mathrm{~nm} \pm \\
0.69 \mathrm{~nm}\end{array}$ & $6.99 \mathrm{~nm} \pm 1.14 \mathrm{~nm}$ \\
& $2.48 \mu \mathrm{m}^{2} \pm$ \\
Surface Area & $1.099 \mu^{2}$ & \\
& $0.09 \mathrm{~m}^{2} \pm 0.070 \mathrm{\mu m}^{2}$ \\
\hline
\end{tabular}

values approach 18 , which is a third of our estimation. ${ }^{27}$ This can possibly be explained by the higher number of bacteria considered for their studies compared with our single-cell analysis.

Internalization of nanobioconjugates was confirmed with the aid of the magnetic force module of the AFM instrument. In this case, images of magnetic fields on the sample are acquired by incorporating a magnetic probe into the AFM. Here we explored the electrostatic force components of the force, which are purely attractive and generate a contrast that appears dark for regions where a metal structure is present. ${ }^{40}$ Accordingly, Figure $3 \mathrm{~F}$ qualitative shows that dark regions, i.e., where the MNPs are present, located within the bacterium cells. A similar experiment in the absence of nanobioconjugates failed to produce any recordable electrostatic forces (data not shown).

Further SEM imaging analysis of bacteria in the presence of nanobioconjugates was conducted to confirm the notion that no significant changes in the integrity of $E$. coli cells occur upon internalization. Images cells and nanobioconjugates prior to delivery are shown in Figure 4A and B, respectively. Aggregates of the nanobioconjugates of about $200 \mathrm{~nm}$ are observable in Figure 4A with white deposits of buffer salts surrounding them. E. coli cells in Figure 4B shows the typical rod-like morphology with 


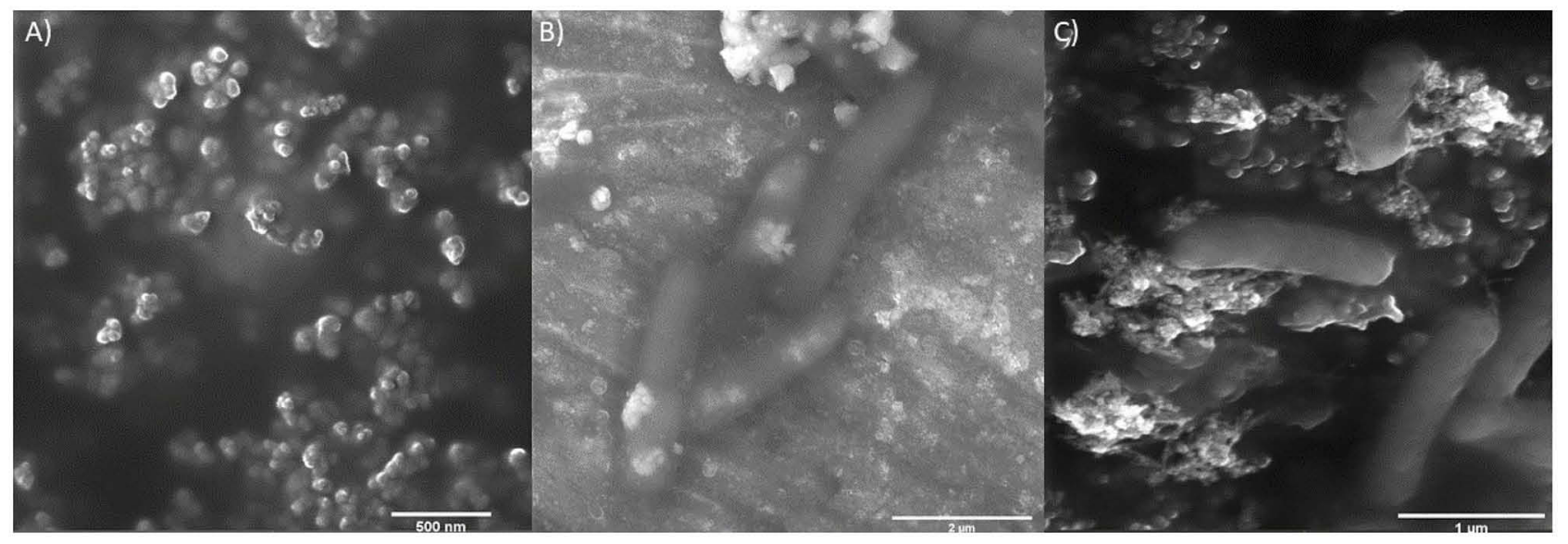

Figure 4 SEM images of (A) nanoparticles at $79 \mathrm{kx}$. Scale bar corresponds to $500 \mathrm{~nm}$, (B) E. coli at $46.2 \mathrm{kx}$. Scale bar corresponds to $2 \mu \mathrm{m}$ and (C) E. coli after exposure to BUF-II-PEA-magnetite nanobioconjugates at $79 \mathrm{kx}$. Scale bar corresponds to I $\mu \mathrm{m}$.

some superficial features that can be attributed to electrostatically attached buffer salts. Figure $4 \mathrm{C}$ shows that after delivery of the nanobioconjugates, E. coli cells appear with an even membrane surface and no significant alterations in size or morphology. This result agrees well with the absence of surface irregularities detected by AFM.

\section{Cellular Delivery And Endosome Escape}

To evaluate whether BUF-II maintained its translocation capacity after immobilization, THP-1, HaCaT, and HFF cells were exposed to the BUFII-FITC-PEA-Magnetite and BUFII-Rhodamine B-PEA-Magnetite nanobioconjugates. Subsequent internalization was assessed with the aid of confocal microscopy. As observed in Figure 5, we confirmed that the nanobioconjugates effectively translocated both cell and nuclear membranes, and distributed homogeneously at the intracellular level in all studied cell lines. In our previous work, ${ }^{24}$ the synthesized nanobioconjugates were only able to penetrate the cell membrane, and we also showed that the peptide alone remained mostly in the cell membrane. The ability of the new vehicle to come across the nuclear membrane makes it superior for a number of applications in gene delivery compared with other drug delivery vehicles. ${ }^{41}$

Endosome escape upon internalization was assessed for BUFII-Rhodamine B-PEA-Magnetite nanobioconjugates via colocalization in the presence of LysoTracker Green ${ }^{\circledR}$ as an endosome marker and changes in thermal energy. Figure 6A and B show representative images for internalization of the nanobioconjugates and formed endosomes in THP-1 cells. Colocalization of Lysotracker and nanobioconjugates approached 27干
$12 \%$, which means that the remaining $73 \mp 12 \%$ of the conjugates are able to escape endosomes. Figure $6 \mathrm{C}$ shows that incubation at low temperatures led to a homogeneous intracellular distribution, which confirmed that internalization is most likely an energy-independent and non-endocytic process. $^{42}$ The direct translocation mechanism and subsequent internalization through a non-endocytic pathway are advantageous for assuring that delivered drugs remain active as they are protected from enzymatic digestion within lysosomes. ${ }^{5}$ The ability of BUF-II to translocate the cell membrane can be associated with the presence of four arginine residues in its structure. This is in line with the work by Kauffman et al. according to which arginine-rich peptides can be transported across the membrane without disrupting it. ${ }^{43}$

\section{Nanobioconjugate Uptake On Mammalian Cells}

The efficiency of the nanobioconjugates at entering mammalian cells was evaluated with the aid of a spectrofluorometer. BUFII-Rhodamine B-PEA-Magnetite nanobioconjugates were delivered and subsequently incubated with THP-1 cells for $1 \mathrm{hr}$ at $37^{\circ} \mathrm{C}$. The difference in fluorescence intensity prior to and after delivery was correlated with the percentage of conjugates internalized. Figure 7 shows the internalized percentage as a function of the initial concentration of nanobioconjugates to which cells were exposed. This curve reaches saturation (i.e., $100 \%$ internalization) at about $250 \mu \mathrm{g} / \mathrm{mL}$. Internalization of half of nanobioconjugates is achieved at $50 \mu \mathrm{g} / \mathrm{mL}$, which lies in the middle of the linear regime of uptake. An internalization efficiency of about $75 \%$ was achieved at $100 \mu \mathrm{g} / \mathrm{mL}$, a concentration at which 


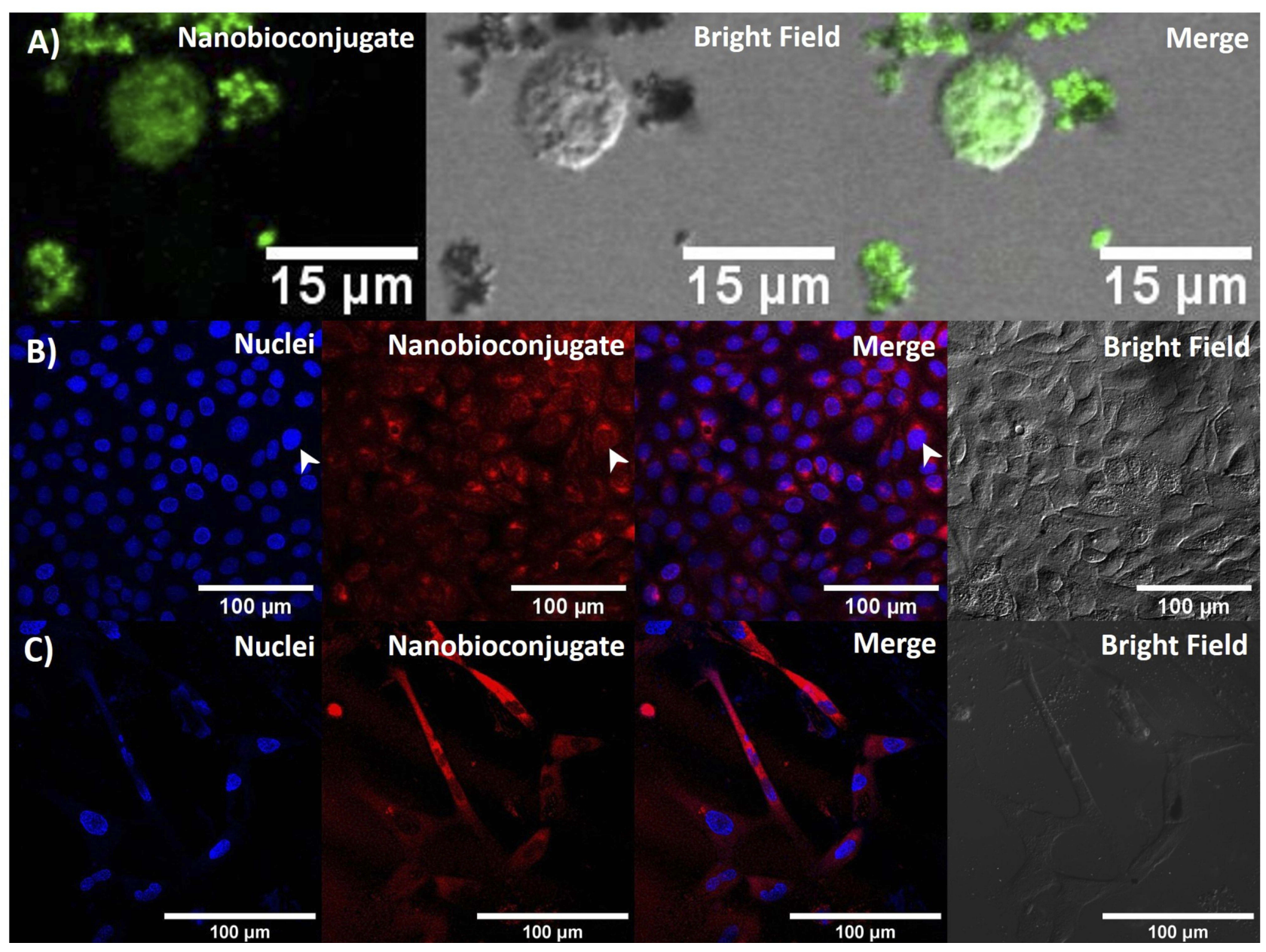

Figure 5 (A) Confocal microscopy images of effective cellular and nuclear internalization of BUF-II-PEA-magnetite nanobioconjugates in THP-I cells. Scale bar corresponds to $15 \mu \mathrm{m}$. (B) Effective cellular and nuclear internalization of BUF-ll-PEG-magnetite in $\mathrm{HaCaT}$ cells. Scale bar corresponds to $50 \mu \mathrm{m}$. (C) Effective cellular and nuclear internalization of BUF-II-PEA-magnetite conjugates in HFF cells. Scale bar corresponds to $50 \mu \mathrm{m}$.

biocompatibility is still acceptable for most delivery applications (see below).

\section{Biocompatibility}

To determine the potential as a drug delivery vehicle, the obtained BUFII-PEA-Magnetite nanobioconjugates need to be biocompatible. According to the ISO 10993 standard to assure biocompatibility of nanomaterials a number of tests are required including hemolysis, platelet aggregation, and cytotoxicity. ${ }^{44}$ As shown in Figure $2 \mathrm{~B}$, hemolysis levels remained below 5\%, which complies with the ISO standard. Figure 2C shows that PEA-coated magnetite and BUFII-PEA-Magnetite nanobioconjugates cause more platelet aggregation than the positive controls epinephrine, ADP, and collagen in all the evaluated concentrations. A slight reduction in aggregation was observed; however, after conjugation of BUFII on the PEA-modified nanoparticles. Bare magnetite causes little aggregation and consequently, it can be categorized as a poor platelet aggregator. The aggregation tendency of BUF-II can be in part attributed to sharing the sequence identity of the N-terminus of $\mathrm{H} 2 \mathrm{~A}$ histone, ${ }^{6}$ which has been reported to induce thrombin generation and subsequently activate the coagulation pathway. Also, extracellular histones are capable of binding to platelets, which in turn leads to increased calcium influx, activation, and ultimately aggregation. ${ }^{45}$ Finally Figure 2D shows that at the highest concentration evaluated (i.e., $100 \mu \mathrm{g} /$ $\mathrm{mL}$ ), cell viability for BUF-II-PEA-magnetite nanobioconjugates remains above $85 \%$ at $24 \mathrm{hrs}$ while after $72 \mathrm{hrs}$ it decreases to $75 \%$. Taken together, these results are encouraging to proceed to the in vivo evaluation of the developed cell-penetrating vehicles.

\section{Conclusion}

Overcoming the low-penetration capacity of a number of pharmacological compounds represents a major challenge 


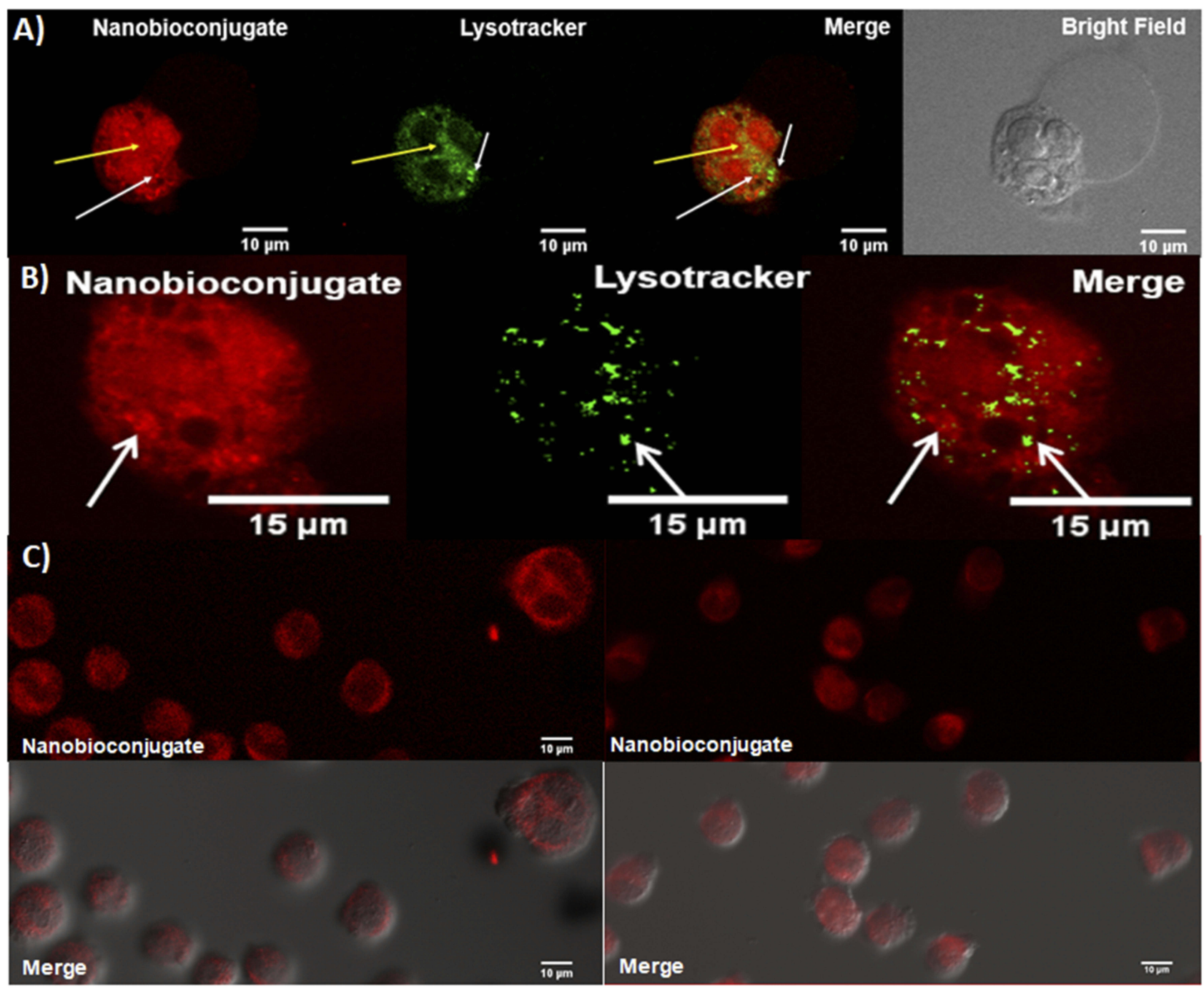

Incubation temperatura: $37^{\circ} \mathrm{C}$

Incubation temperatura: $4^{\circ} \mathrm{C}$

Figure 6 (A) Simultaneous delivery of LysoTracker Green and BUFII-Rhodamine B-PEA-Magnetite nanobioconjugates to evaluate endosome escape in THP-I cells. White arrows point to some of the regions where no colocalization was found between the nanobioconjugate and the Lysotracker while the yellow arrow corresponds to highly colocalized regions. Scale bar corresponds to $10 \mu \mathrm{m}$ (B) Zoom in to an individual THP-I cell after delivery of LysoTracker Green ${ }^{\circledR}$ and BUFII-Rhodamine B-PEA-Magnetite nanobioconjugates. White arrows point to regions of low colocalization. Scale bar corresponds to $10 \mu \mathrm{m}(\mathrm{C}) \mathrm{THP}-\mathrm{I}$ cells incubated with the nanobioconjugates at $37^{\circ} \mathrm{C}$ and subsequent incubation at $4^{\circ} \mathrm{C}$ for 2 hrs. No significant changes in fluorescence intensity upon incubation at different thermal energy support the notion that cellular internalization of BUFII-Rhodamine B-PEA-Magnetite nanobioconjugates proceeds through an energy-independent pathway. Scale bar corresponds to I0 $\mu \mathrm{m}$.

for the pharmaceutical industry. To potentially overcome this issue, we have recently introduced novel cell-penetrating vehicles by interfacing the nanostructured material magnetite with the antimicrobial peptide Buforin II (BUF-II). The obtained nanobioconjugates were capable of translocating the cell membrane without significantly decreasing viability. A major drawback, however, was the complete loss of antimicrobial activity. Here, we overcome that issue by immobilizing BUF-II on polyetheramine-modified magnetite nanoparticles. We hypothesized that by introducing this surface spacer, the residues of BUF-II responsible for the antimicrobial activity remain largely accessible to block the replication machinery of bacteria. Characterization of the synthesized nanobioconjugates via TGA and FTIR confirmed the success and of each conjugation step. Size in aqueous solution via DLS was of about $350 \mathrm{~nm}$ while TEM in the dry state confirmed the presence of agglomerates formed by individual particles of about $10 \mathrm{~nm}$. AFM and SEM images verified successful translocation in $E$. coli without promoting significant membrane alterations. Delivery in THP-1, HaCaT and HFF cells demonstrated internalization, homogeneous intracellular distribution, and nuclear penetration. Colocalization with Lysotracker showed an endosomal escape efficiency of about 73干 


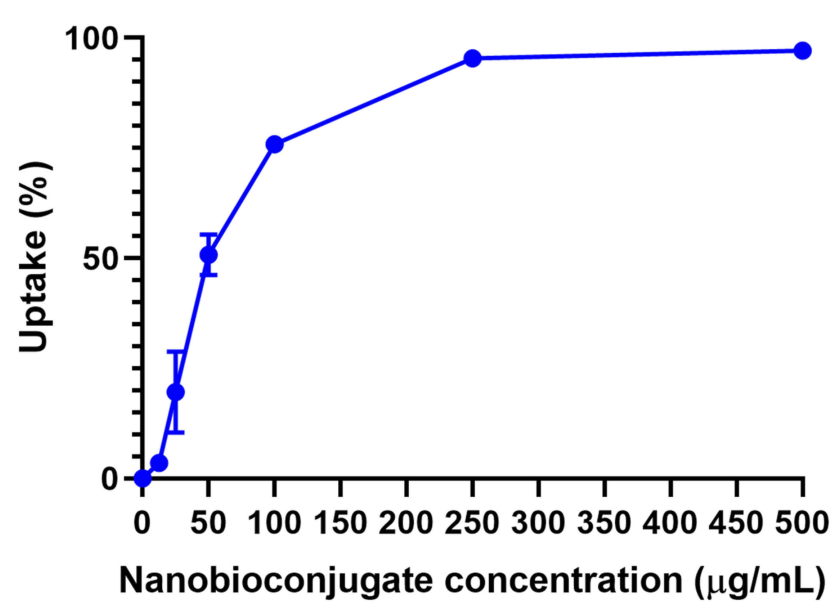

Figure 7 Uptake efficiency of BUFII-Rhodamine B-PEA-Magnetite nanobioconjugates on THP-I cells. The efficiency was calculated by measuring the fluorescence intensity prior to and after cellular delivery of the nanobioconjugates. Saturation was achieved for concentrations above $250 \mu \mathrm{g} / \mathrm{mL}$. A linear uptake regime was observed up to about $50 \mu \mathrm{g} / \mathrm{mL}$.

$12 \%$ in THP-1 cells. Avoidance of endocytic pathways of internalization was qualitatively confirmed by a delivery assay at low temperature. The nanobioconjugates are highly biocompatible as demonstrated by hemolysis levels below $5 \%$ and acute cytotoxicity of around $85 \%$. A surprisingly high thrombogenicity was observed, could be potentially useful for applications in regeneration where a sustained platelet activation is beneficial. Our findings show a promissory vehicle for cell-penetration and microbial control with the capability of escaping endocytic internalization pathways and reaching nuclei. This makes the vehicle addressable for a number of applications ranging from antimicrobial topical treatments to the delivery of nucleotides and therapeutic molecules with difficulties to bypass cell membranes.

\section{Acknowledgments}

This research was funded by Colciencias grant 689-2018. Also, funding from the Department of Biomedical Engineering and by the Fondo de Apoyo a Profesores Asistentes (Research Support Fund for Assistant Professors [FAPA] to Carolina Muñoz and Juan Carlos Cruz), Universidad de los Andes, is gratefully acknowledged. We would like to thank the Department of Chemical Engineering for providing access to the TGA instrument. Finally, we would like to thank the Microscopy Core Facility for access to the instruments and technical support with the confocal and AFM microscopes.

\section{Disclosure}

The authors report no conflicts of interest in this work.

\section{References}

1. Kristensen M, Birch D, Mørck Nielsen H, Kristensen M, Birch D, Mørck Nielsen H. Applications and challenges for use of cell-penetrating peptides as delivery vectors for peptide and protein cargos. Int J Mol Sci. 2016;17(2):185. doi:10.3390/ijms17020185

2. Komin A, Russell LM, Hristova KA, Searson PC. Peptide-based strategies for enhanced cell uptake, transcellular transport, and circulation: mechanisms and challenges. Adv Drug Deliv Rev. 2017;110111:52-64. doi:10.1016/j.addr.2016.06.002

3. Park CB, Kim MS, Kim SC. A novel antimicrobial peptide fromBufo bufo gargarizans. Biochem Biophys Res Commun. 1996;218(1):408413. doi:10.1006/bbrc. 1996.0071

4. Uyterhoeven ET, Butler CH, Ko D, Elmore DE. Investigating the nucleic acid interactions and antimicrobial mechanism of buforin II. FEBS Lett. 2008;582(12):1715-1718. doi:10.1016/j.febslet.2008.04.036

5. Takeuchi T, Futaki S. Current understanding of direct translocation of arginine-rich cell-penetrating peptides and its internalization mechanisms. Chem Pharm Bull (Tokyo). 2016;64(10):1431-1437. doi:10.12 48/cpb.c16-00505

6. Park CB, Yi K-S, Matsuzaki K, Kim MS, Kim SC. Structure-activity analysis of buforin II, a histone H2A-derived antimicrobial peptide: the proline hinge is responsible for the cell-penetrating ability of buforin II. Proc Natl Acad Sci. 2000;97(15):8245-8250. doi:10. 1073/pnas. 150518097

7. Cho JH, Sung BH, Kim SC. Buforins: histone H2A-derived antimicrobial peptides from toad stomach. Biochim Biophys Acta Biomembr. 2009;1788(8):1564-1569. doi:10.1016/j.bbamem.2008. 10.025

8. Afacan N J, Yeung ATY, Pena O M, Hancock R EW. Therapeutic potential of host defense peptides in antibiotic-resistant infections. Curr Pharm Des. 2012;18(6):807-819. doi:10.2174/138161212799277617

9. Alves D, Olívia Pereira M. Mini-review: antimicrobial peptides and enzymes as promising candidates to functionalize biomaterial surfaces. Biofouling. 2014;30(4):483-499. doi:10.1080/08927014.2014. 889120

10. Çevik E, Senel M, Abasiyanik M. Immobilization of urease on copper chelated EC-Tri beads and reversible adsorption. African $J$ Biotechnol. 2013;10(34):6590-6597. doi:10.4314/ajb.v10i34

11. Matsumura Y, Maeda H. A new concept for macromolecular therapeutics in cancer chemotherapy: mechanism of tumoritropic accumulation of proteins and the antitumor agent smancs. Cancer Res. 1986;46(12 Pt 1):6387-6392. 
12. Ma L, Wu G, Zhao M, Li X, Han P, Song G. Modification of carbon fibers surfaces with polyetheramines: the role of interphase microstructure on adhesion properties of CF/epoxy composites. Polym Compos. 2018;39:E2346-E2355. doi:10.1002/pc.24652

13. Abdollahi H, Salimi A, Barikani M, Samadi A, Hosseini Rad S, Zanjanijam AR. Systematic investigation of mechanical properties and fracture toughness of epoxy networks: role of the polyetheramine structural parameters. J Appl Polym Sci. 2019. doi:10.1002/app.47121

14. Arachchige MP, Laha SS, Naik AR, Lewis KT, Naik R, Jena BP. Functionalized nanoparticles enable tracking the rapid entry and release of doxorubicin in human pancreatic cancer cells. Micron. 2017;92:25-31. doi:10.1016/j.micron.2016.10.005

15. Sadighian S, Rostamizadeh K, Hosseini-Monfared H, Hamidi M. Doxorubicin-conjugated core-shell magnetite nanoparticles as dualtargeting carriers for anticancer drug delivery. Colloids Surf B Biointerfaces. 2014;117:406-413. doi:10.1016/j.colsurfb.2014.03.001

16. Huang J, Li Y, Orza A, et al. Magnetic nanoparticle facilitated drug delivery for cancer therapy with targeted and image-guided approaches. Adv Funct Mater. 2016;26(22):3818-3836. doi:10.1002/ adfm. 201504185

17. Rodríguez-Luccioni HL, Latorre-Esteves M, Méndez-Vega J, et al. Enhanced reduction in cell viability by hyperthermia induced by magnetic nanoparticles. Int $J$ Nanomedicine. 2011;6:373-380. doi:10.2147/IJN.S14613

18. Creixell M, Bohórquez AC, Torres-Lugo M, Rinaldi C. EGFR-targeted magnetic nanoparticle heaters kill cancer cells without a sensible temperature rise.SI. ACS Nano. 2011;5(9):3-8. doi:10.1021/ $\mathrm{nn} 201822 \mathrm{~b}$

19. Xu J, Sun J, Wang Y, Sheng J, Wang F, Sun M. Application of iron magnetic nanoparticles in protein immobilization. Molecules. 2014;19(8):11465-11486. doi:10.3390/molecules190811465

20. Moss DM, Siccardi M. Optimizing nanomedicine pharmacokinetics using physiologically based pharmacokinetics modelling. $\mathrm{Br} J$ Pharmacol. 2014;171(17):3963-3979. doi:10.1111/bph.12604

21. Tietze R, Zaloga J, Unterweger H, et al. Magnetic nanoparticle-based drug delivery for cancer therapy. Biochem Biophys Res Commun. 2015. doi:10.1016/j.bbrc.2015.08.022

22. Can K, Ozmen M, Ersoz M. Immobilization of albumin on aminosilane modified superparamagnetic magnetite nanoparticles and its characterization. Colloids Surf B Biointerfaces. 2009;71(1):154159. doi:10.1016/J.COLSURFB.2009.01.021

23. Zhang W, Shi X, Huang J, Zhang Y, Wu Z, Xian Y. Bacitracinconjugated superparamagnetic iron oxide nanoparticles: synthesis, characterization and antibacterial activity. ChemPhysChem. 2012;13 (14):3388-3396. doi:10.1002/cphc.201200161

24. Cuellar M, Cifuentes J, Perez J, et al. Novel BUF2-magnetite nanobioconjugates with cell-penetrating abilities. Int J Nanomedicine. 2018;13:8087-8094. doi:10.2147/IJN.S188074

25. Muñoz-Camargo C, Salazar V, Barrero-Guevara L, et al. Unveiling the multifaceted mechanisms of antibacterial activity of Buforin II and frenatin $2.3 \mathrm{~s}$ peptides from skin micro-organs of the orinoco lime treefrog (sphaenorhynchus lacteus). Int J Mol Sci. 2018;19(8):2170. doi:10.3390/ijms19082170

26. Feng B, Hong RY, Wang LS, et al. Synthesis of Fe3O4/APTES/PEG diacid functionalized magnetic nanoparticles for MR imaging. Colloids Surf A Physicochem Eng Asp. 2008;328(1-3):52-59. doi:10.1016/J.COLSURFA.2008.06.024

27. Chao Y, Zhang T. Optimization of fixation methods for observation of bacterial cell morphology and surface ultrastructures by atomic force microscopy. Appl Microbiol Biotechnol. 2011;92(2):381-392. doi:10.1007/s00253-011-3551-5
28. Camesano TA, Natan MJ, Logan BE. Observation of changes in bacterial cell morphology using tapping mode atomic force microscopy. Langmuir 2000;16(10):4563-4572. doi:10.1021/LA990805O

29. Wen X, Yang J, He B, Gu Z. Preparation of monodisperse magnetite nanoparticles under mild conditions. Curr Appl Phys. 2008;8(5):535541. doi:10.1016/J.CAP.2007.09.003

30. Valenzuela R, Fuentes MC, Parra C, et al. Influence of stirring velocity on the synthesis of magnetite nanoparticles (Fe3O4) by the co-precipitation method. J Alloys Compd. 2009;488(1):227-231. doi:10.1016/j.jallcom.2009.08.087

31. Ling D, Lee N, Hyeon T. Chemical synthesis and assembly of uniformly sized iron oxide nanoparticles for medical applications. Acc Chem Res. 2015;48(5):1276-85 doi:10.1021/acs.accounts.5b00038

32. Karimzadeh I, Aghazadeh M, Ganjali MR, et al. A novel method for preparation of bare and poly(vinylpyrrolidone) coated superparamagnetic iron oxide nanoparticles for biomedical applications. Mater Lett. 2016. doi:10.1016/j.matlet.2016.05.048

33. Rawle A. Basic principles of particle size analysis. Surf Coatings Int. 2003

34. Berne BJ, Pecora R. Dynamic Light Scattering : With Applications to Chemistry, Biology, and Physics. Dover Publications; 2000.

35. Shameli K, Bin Ahmad M, Jazayeri SD, et al. Synthesis and characterization of polyethylene glycol mediated silver nanoparticles by the green method. Int J Mol Sci. 2012;13(6):6639-6650. doi:10.3390/ ijms13066639

36. Yamaura M, Camilo RL, Sampaio LC, Macêdo MA, Nakamura M, Toma HE. Preparation and characterization of (3-aminopropyl) triethoxysilane-coated magnetite nanoparticles. J Magn Magn Mater. 2004;279(2-3):210-217. doi:10.1016/j.jmmm.2004.01.094

37. Kobayashi S, Chikushi A, Tougu S, et al. Membrane translocation mechanism of the antimicrobial peptide buforin 2. Biochemistry. 2004;43(49):15610-15616. doi:10.1021/bi048206q

38. Matsuzaki K, Harada M, Funakoshi S, Fujii N, Miyajima K. Physicochemical determinants for the interactions of magainins 1 and 2 with acidic lipid bilayers. BBA - Biomembr. 1991. doi:10.10 16/0005-2736(91)90366-G

39. Hee Lee IN, Cho Y, Lehrer RI. Effects of $\mathrm{pH}$ and salinity on the antimicrobial properties of clavanins. Infect Immun. 1997;65 (7):2898-2903.

40. Gomez RD, Pak AO, Anderson AJ, Burke ER, Leyendecker AJ, Mayergoyz ID. Quantification of magnetic force microscopy images using combined electrostatic and magnetostatic imaging. J Appl Phys. 1998. doi:10.1063/1.367638

41. Chou LYT, Ming K, Chan WCW. Strategies for the intracellular delivery of nanoparticles. Chem Soc Rev. 2011;40(1):233-245. doi:10.1039/C0CS00003E

42. GUO Z, PENG H, KANG J, SUN D. Cell-penetrating peptides: possible transduction mechanisms and therapeutic applications. Biomed Rep. 2016. doi:10.3892/br.2016.639

43. Kauffman WB, Fuselier T, He J, Wimley WC. Mechanism matters: a taxonomy of cell penetrating peptides. Trends Biochem Sci. 2015;40 (12):749-764. doi:10.1016/j.tibs.2015.10.004

44. CDRH. Use of International Standard ISO 10993-1, "Biological evaluation of medical devices-part 1: evaluation and testing within a risk management process" guidance for industry and food and drug administration staff preface public comment; 2016. Available from: http://www.regulations.gov. Accessed October 3, 2018.

45. Hoeksema M, Van Eijk M, Haagsman HP, Hartshorn KL. Histones as mediators of host defense, inflammation and thrombosis. Future Microbiol. 2016. doi:10.2217/fmb.15.151 


\section{Publish your work in this journal}

The International Journal of Nanomedicine is an international, peerreviewed journal focusing on the application of nanotechnology in diagnostics, therapeutics, and drug delivery systems throughout the biomedical field. This journal is indexed on PubMed Central, MedLine, CAS, SciSearch ${ }^{\mathbb{R}}$, Current Contents ${ }^{\mathbb{B}} /$ Clinical Medicine,
Journal Citation Reports/Science Edition, EMBase, Scopus and the Elsevier Bibliographic databases. The manuscript management system is completely online and includes a very quick and fair peer-review system, which is all easy to use. Visit http://www.dovepress.com/ testimonials.php to read real quotes from published authors.

Submit your manuscript here: https://www.dovepress.com/international-journal-of-nanomedicine-journal 